\title{
Identifying Ecological Red Lines: A Case Study of the Coast in Liaoning Province
}

\section{Chuansheng Wang ${ }^{1, *}$, Guiyan Sun ${ }^{1,2}$ and Lijuan Dang 1,2}

1 Key Laboratory of Regional Sustainable Development Modeling, Institute of Geographic Sciences and Natural Resources Research, Chinese Academy of Sciences, Beijing 100101, China; E-Mails: sungy.12b@igsnrr.ac.cn (G.S.); danglijuan@gmail.com (L.D.)

2 University of Chinese Academy of Sciences, Beijing 100049, China

* Author to whom correspondence should be addressed; E-Mail: wangsc@igsnrr.ac.cn; Tel.: +86-10-6488-9817.

Academic Editor: Marc A. Rosen

Received: 25 March 2015 / Accepted: 13 July 2015 / Published: 17 July 2015

\begin{abstract}
The global decline in estuarine and coastal ecosystems is affecting critical ecosystem services. The spatial agglomeration of population, industries and resources has led to the emergence of regionally-specific ecological problems. Therefore, identifying "ecological red lines", based on specific natural and environmental features, could help to differentiate the economic development and ecological protection directions or potentials of different regions in future. The aim of this case study is to define the ecological red line in the coastal zone of Liaoning Province, China, by evaluating the ecological importance and environmental stress in its marine and terrestrial ecosystems. For this purpose, the ecological importance of this area was first classified into four conservation indices (species, wetland, water and coast and islands) and assigned values of 5, 3 and 1 for indications of high, moderate and minor importance. In the meantime, environmental stress was also classified into four indices (water environment, salinization, soil erosion and erosion of coasts and islands) and assigned values of 5, 3 and 1 for indications of high, moderate and low stress, respectively. Then, based on an overlay analysis and evaluation of the above results, we defined two grades of ecological red line zones. Grade I ecological red line zones contain the areas with critical and diverse ecosystem services, areas of high importance for species conservation and nature reserves, as well as ecologically-vulnerable and sensitive areas. It is important in these areas to maintain the biological diversity and to improve the quality of the ecological environment, which should be strictly protected and explicitly controlled. Grade II ecological red line zones display areas with minimum requirements for maintaining
\end{abstract}


the basic needs of a livable environment and human health, moderate to minor levels of ecological importance and high to moderate levels of environmental stress. To better control and protect such ecological red lines, setting up an ecological inventory through remote sensing satellites and ground-level monitoring and appraising the effectiveness of dynamical protection are highly recommended.

Keywords: coastal zone; ecological red line; evaluation; Liaoning Province

\section{Introduction}

Owing to their advantageous locations and the richness of their marine and mineral resources, coastal areas have become the major choice of location for residences and industry [1]. Coastline areas are highly populated, and nearly half of the world's population lives in coastal areas, which benefit human society with access to trade, land development, oil and gas exploration and food production [2,3]. Coastal and ocean activities not only affect the economies of nations, but are also home to species and habitats that provide many benefits to social and natural ecosystems. However, with the rapid economic development in recent years, increasing amounts of natural resources are being consumed, and ecosystems in coastal areas are becoming more sensitive and vulnerable [4,5]. In fact, according to the Marine Environmental Quality Report of 2012 [6], the offshore seawater environment in China has continuously worsened in recent years. The area of waters with a Grade IV (the quality of water is poor, including marine port waters and marine development operation zones) and below has reached $9.26 \times 10^{4} \mathrm{~km}^{2}$, which is an increase of $26 \%$ since 2011 . The greatest increase, accounting for $36.84 \%$ of the total, occurred in the Bohai Sea.

The competition between economic development and resource exploitation in coastal areas has gradually intensified [7,8]. Because of this growth, as well as increased wealth and affluence, demands on coastal and marine resources for both aesthetic enjoyment and economic benefits are rapidly increasing [9]. Additionally, climate change could affect coastal areas in a variety of ways [10]. Human-made infrastructure and coastal ecosystems are sensitive to sea level rise, increasing salinity levels, coastal erosion and water pollution [11,12]; coastal habitats are also heavily susceptible to depletion and degradation due to unplanned development activities that cause irreversible damage $[13,14]$. The impacts of climate change are likely to worsen those existing problems in coastal and marine areas. These concerns indicate the growing conflicts between development and coastal and marine resource use, which could slow down sustainable development in coastal regions.

Over the last three decades, China's government has been trying to promote the integration of economic development and environmental protection. A number of approaches, for example reverting farmland to forests and grassland [15], have been taken to set aside nature reserves, wetlands, forested parks, and so on, but the effects have been insignificant [16]. Nowadays, addressing the additional stresses of climate change may require new approaches to managing those ecosystems. Under such circumstances, drawing an "ecological red line" (ERL) is timely and imperative. In the communique at the Third Plenum in 2013 [17] (where China's major leaders participate in a discussion of national development strategies), an "ERL" was explicitly put forward for the first time for the purpose of 
ecological protection and was proposed to be implemented by a paid use system, for example companies should pay for the use of resources and provide compensation for ecological damage. The drawing of this ERL is of great significance for China, as the development of the country and the livelihood of its people are severely constrained by resource shortages, as well as by pollution and the destruction of the environment. The government also started pilot work on the determination of an ERL to offset the feasibility of the technical methodology. Inner Mongolia, Jiangxi, Guangxi and Hubei Provinces in China have, for the most part, completed their provincial schemes for the determination of their ERLs. This paper explores the principles, basis and methodology for identifying what should be the ERLs of coastal regions by constructing a scheme for such an evaluation and identification. This research also has the potential to be used in academic studies of ERLs and, hence, advances future research on this topic.

\section{Study Method}

\subsection{Study Area}

The coastal region in Liaoning Province stretches from the Bohai Sea to the Yellow Sea, extending from the eastern mouth of the Yalu River to the western Shanghaiguan Laolongtou. The coastline is $2110 \mathrm{~km}$ long and reaches from the cities of Dandong, Dalian, Yingkou, Panjin, Jinzhou and Huludao to the county of Suizhong. The industrial added value and the rate of urbanization accounted for $49 \%$ and $60 \%$ of the province, respectively. Recently, the focus of the development strategy of the government has shifted to coastal regions, which has exacerbated the deterioration of the ecosystems and environment. The sea area north of the Yellow Sea and Liaodong Bay is the major area of water with a Grade IV standard. According to data from the National Bureau of Statistics, the extent of reed wetlands in the mouth of Shuangtaizi River in the Panjin coast has decreased by $60 \%$ since the 1980 s, due to many reed wetlands having been reclaimed into farmland. Moreover, the sea area in Jinzhou Bay has diminished by $43 \%$ from 2007 to 2011, with the mouth of the bay having narrowed and the river having become smaller and shallower.

Based on extensive field research into land use in Liaoning, we found that over $700 \mathrm{~km}^{2}$ of the land resources have been exploited by urban renewal and construction in 2010. These changes led to the natural shoreline making up less than $1 / 3$ of the total coast, with about $1 / 3$ of the sandy coast having become eroded. Considering the current plan for land use of coastal cities and that most of the tidal flats have already been transformed into industrial areas, there is the potential for massive land reclamation in the future. Overall, the major ecological problems for the coastal area are as follows: high emissions of pollution and the resulting damage in marine functions; rapid expansion of land reclamation, sharply declining wetlands area and decreasing biodiversity [18]; excessive exploitation of groundwater, increasing salinization of the soil and increasing seawater intrusion [19]; and occasional oil spills, lack of water resources and frequent oceanic disasters of various types. Such ecological problems seriously jeopardize the safety of coastal red line zones.

This study assessed 33 coastal cities and counties and their coastal waters; the inland area and the area of these sea waters are $3.7 \times 10^{4} \mathrm{~km}^{2}$ and $4.2 \times 10^{4} \mathrm{~km}^{2}$, respectively. The inland study area covers western hilly areas in Liaoning, the Liaohe River Plain, the Liaodong Peninsula, Qian Mountains' sierra and the Changshan archipelago, while the sea waters in the study area include 
Liaodong Bay, the Bohai Sea and the north Yellow Sea. The coast in Liaoning consists of the Liaodong Peninsula and the Qian Mountains' sierra to the east, western hilly areas and the Liaohe River Delta plain in the east and west (Figure 1). There are five coastal ecosystems in Liaoning: mountain-forest, plain-farmland, river-wetland, coastal wetlands and offshore waters. The shoreline coast types are bedrock, sandy and silt coasts (estuarine silt and rocky silt).

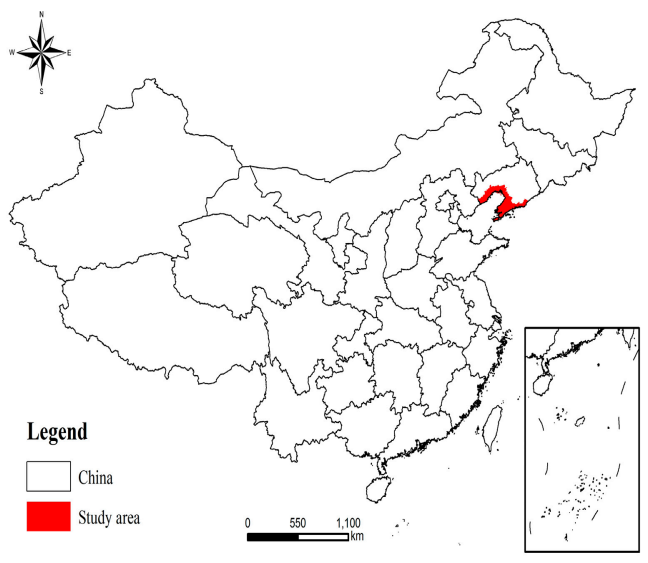

(a)

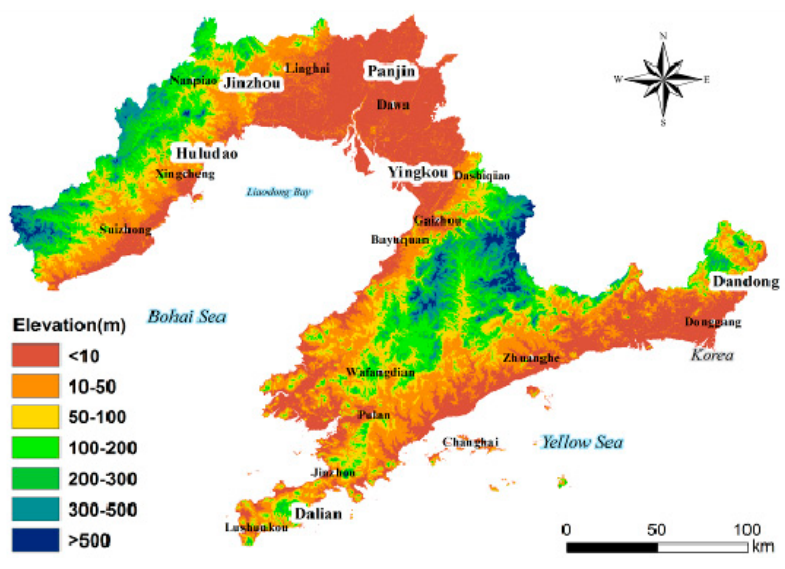

(b)

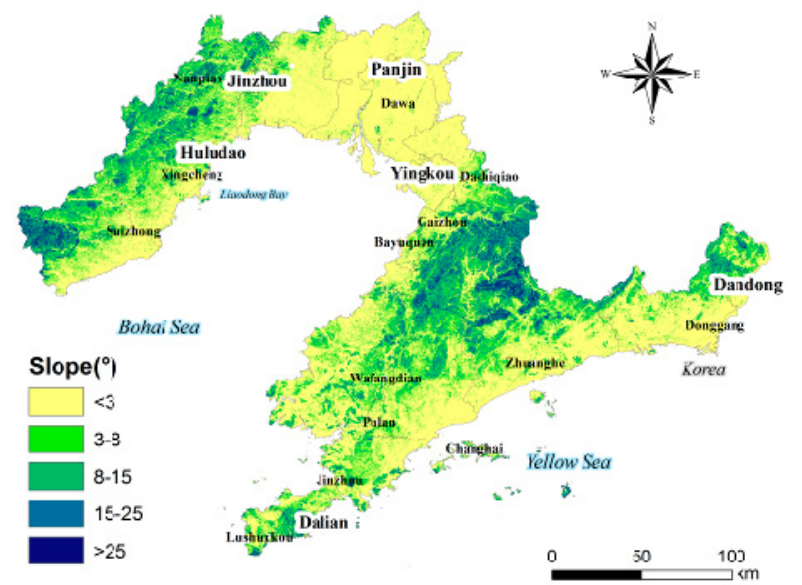

(c)

Figure 1. Coastal (a) location; (b) elevation and (c) slope in Liaoning, China.

\subsection{General Principle for Identifying ERL Zones}

According to the spatial differences of ecological protection and economic development, identifying ERL should follow several principles.

(1) Ecological protection priority:

The determination of a marine functional zone and exploitation of ERL zones in Liaoning should be based on the premise of protecting and preserving the natural landscape and its functions, which, in turn, are based on the natural attributes of the landscapes and marine resources of the coastal areas. Preservation and protection of the marine ecological environment should be the top priority. The ecological environment of each functional zone could be strictly protected under this principle. 
(2) Integrity of the ecosystem and of ecological processes:

Ecosystems at different scales should not be limited by administrative boundaries. The administration of the different regions should coordinate their evaluations of ecosystem integrity and ecological processes to ensure continuity of the ecosystems across regional boundaries.

(3) Dominant indicator functions:

The identification of the dominant ecological function in each zone should consider the relationship between adjacent sections, take into account the interactions between the ecological functions of zones and consider the environmental protection needs of coastal, inland and marine ecosystems. Moreover, the utilization of coastlines across all industries should be coordinated, to avoid encroaching on the marine ecosystem and landscape and to avoid exploiting coastline resources. It is necessary to optimize the layout of marine industries by adjusting the functions of coastal zones to promote coastal ecological services and to assure the comprehensive, sustainable and coordinated development of ocean economics.

(4) Coordinated planning and zoning:

The ecological functional orientation of coastal zones in Liaoning could be coordinated among Major Function-Oriented Zone Planning, Major Function Zoning of Liaoning Province, Marine Functional Zoning of Liaoning and other socio-economic planning initiatives, as well as special plans at the city or county level. ERL identification must include marine and terrestrial ecosystems. The identification of terrestrial areas based on ecosystem assessment from the Major Function Region Planning of Liaoning Province introduced the capacity of the environment, ecological importance and vulnerability, natural hazards and other indices. The evaluation and identification of marine areas was based on data from the Marine Function Zoning of Liaoning Province.

(5) Maintaining a balance between ecological environment and sustainable development:

ERL identification is a new way for integrating the development of the social economy, protection of the ecological environment and utilization of natural resources in a regionally-specific manner. It should be carried out under the principle of reconstructing sustainable relationships between humans, ERLs, landscapes and natural systems.

\subsection{Method to Evaluate Ecological Environments}

Based on the DEM (digital elevation model) cell size of $30 \mathrm{~m}$, land use data, Marine Functional Zoning and the criteria and methodology on the eco-regulation functional division from the National Ecological Function Zoning [20], this paper adopts an index rating system to evaluate the ecological importance and environmental stress by using the comprehensive assessment and recognition method (use of multiple indicators to evaluate and then classifying the results of the evaluation). Each of the indices was subcategorized into four conservation types (species, wetland, water and coast and islands), with four types of environmental stress (water environmental stress, salinization stress, soil erosion stress, coastal and island erosion stress). These two types of indices should be calculated as follows:

Ecological importance $=$ MAX [species conservation, wetland conservation, water conservation, coast and island conservation] 
Environmental stress $=$ MAX [water environmental stress, salinization stress, soil erosion stress, coastal and island erosion stress]

The evaluation method and basis for each single index are as follows.

\subsection{ERL Identification Steps}

The ERL category and boundary were identified by applying the following steps (Figure 2):

Step 1, single-index classification: We employed the topography data at a resolution of $30 \mathrm{~m}$ and land use data from land resources surveys of 33 coastal counties, as well as the database of Marine Functional Zoning of Liaoning, from which the land use data and functional zoning type were extracted. The land use data included 16 secondary land types: orchards, other horticultural areas, forests, bush forest land, woodland, natural meadows, planting pastures, other grasslands, rivers, lakes, reservoirs, ponds, inland and coastal tidal flats, canals and ditches and hydro-construction lands, as indicated by the Current Land Use Condition Classification issued in 2007. There are five types of marine functional zones: those that are marine preserves, agricultural and fishery, tourist recreational, specially designated and reserved. We established two first-class indices based on eight second-class indicators by using land use data and functional zoning, as well as other ecological investigations and environmental monitoring data. The first-class index included ecological importance and environmental stress. The ecological importance was comprised of four conservation subcategories: species, wetland, water and coast and islands; the environmental stress was also comprised of four subcategories, which were water environment, salinization, soil erosion and coastal and island erosion. Single-index classification maps were generated according to the evaluation criteria of Tables 1 and 2.

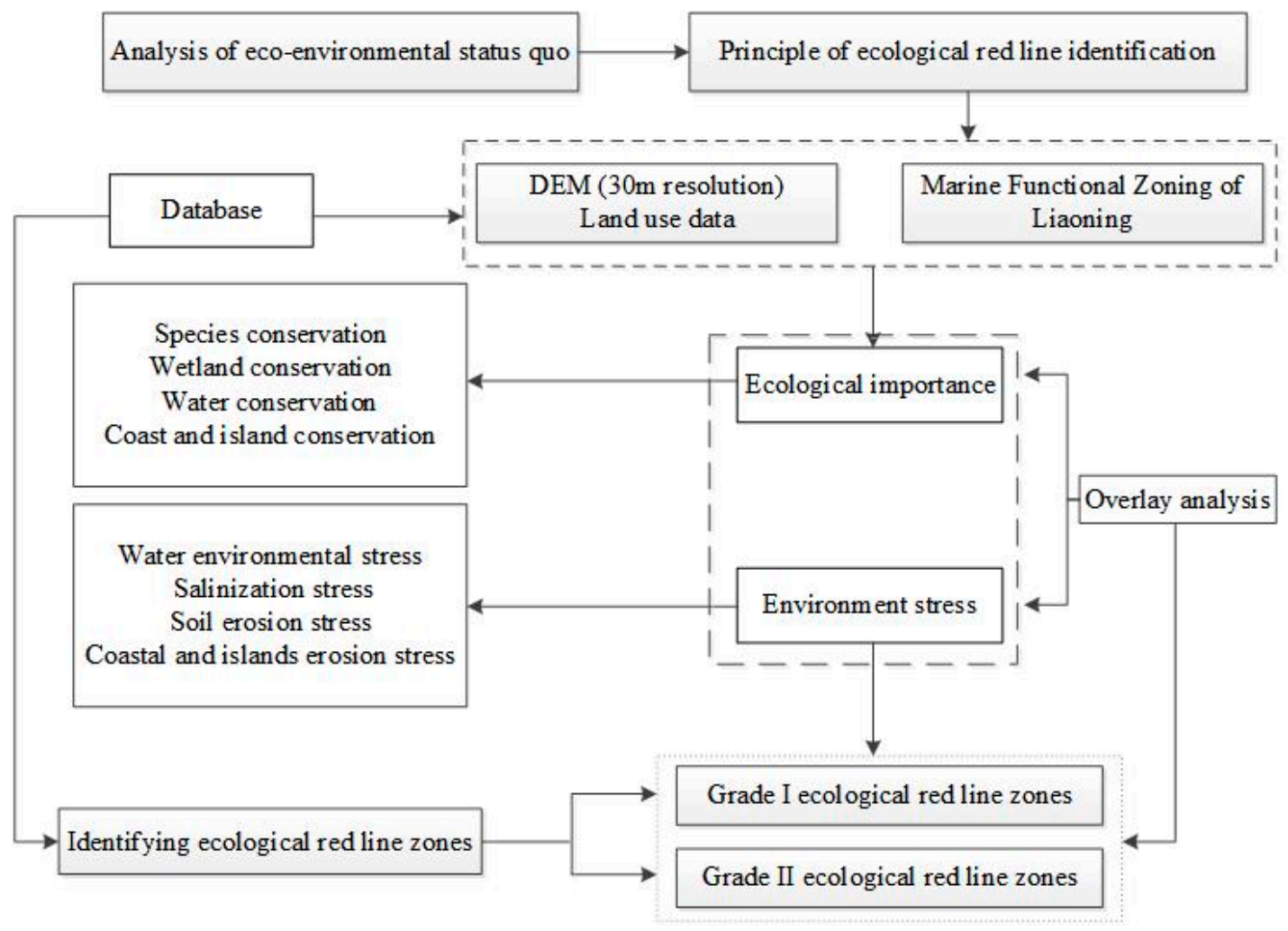

Figure 2. Flowchart outlining the approach used to develop ecological red line identifications. 
Table 1. Evaluation basis for the index of ecological importance.

\begin{tabular}{|c|c|c|}
\hline Index & Value & Evaluation Basis \\
\hline \multirow{3}{*}{$\begin{array}{c}\text { Species } \\
\text { conservation }\end{array}$} & 5 & $\begin{array}{l}\text { National or provincial nature reserves and forested parks; more than } 30 \% \text { of land dedicated to priority } \\
\text { ecosystems and maintenance of species diversity; Grade I for a specifically endangered sea habitat. }\end{array}$ \\
\hline & 3 & $\begin{array}{l}\text { Sub-provincial nature reserves and forested parks; ratio of species number is between } 5 \% \text { and } 30 \% \text {; } \\
\text { Grade II and lower species and fishery conservation area. }\end{array}$ \\
\hline & 1 & Other forested and grassland ecosystems, as well as reserve area of Marine Functional Zoning. \\
\hline \multirow{3}{*}{$\begin{array}{c}\text { Wetland } \\
\text { conservation }\end{array}$} & 5 & National or provincial wetland in current and long-term planning. \\
\hline & 3 & Natural wetland located in coastal region with an area $>1 \mathrm{~km}^{2}$; wetlands distributed in major estuaries. \\
\hline & 1 & $\begin{array}{l}\text { Natural or constructed wetlands with elevation }<5 \mathrm{~m} \text { and area }<1 \mathrm{~km}^{2} \text {; natural wetlands located in other } \\
\text { estuarine areas and tidal flats in coastal area. }\end{array}$ \\
\hline \multirow{3}{*}{$\begin{array}{c}\text { Water } \\
\text { conservation }\end{array}$} & 5 & $\begin{array}{l}\text { Forest, grassland, and wetland ecosystem with elevations }>200 \mathrm{~m} \text { i,ii; Grade I sanitary standard for } \\
\text { drinking water and groundwater. }\end{array}$ \\
\hline & 3 & Orchards with elevation $>200 \mathrm{~m}$ iii; ecological region with elevation $<200 \mathrm{~m}$ and slope $<15^{\circ}$. \\
\hline & 1 & $\begin{array}{l}\text { Other ecological region with elevation }>200 \mathrm{~m} \text { and slope }>15^{\circ} \text {; an ecological region with an elevation } \\
<200 \mathrm{~m} \text { and slope between } 8^{\circ} \text { and } 15^{\circ} \text {. }\end{array}$ \\
\hline \multirow{3}{*}{$\begin{array}{l}\text { Coast and island } \\
\text { conservation }\end{array}$} & 5 & $\begin{array}{l}\text { Grade I coast and bay landscape and coast or marine tourism resources conservation area; the length of } \\
\text { a sandy or bedrock coast }>10 \mathrm{~km} \text {. }\end{array}$ \\
\hline & 3 & $\begin{array}{l}\text { Grade II coast and bay landscape and coast or marine tourism resources conservation area; the length of } \\
\text { a sandy or bedrock coast }<10 \mathrm{~km} \text {. }\end{array}$ \\
\hline & 1 & Other oceanic islands. \\
\hline
\end{tabular}

Note: ${ }^{\mathrm{i}}$ The areas of elevation $>200 \mathrm{~m}$ account for $13.7 \%$ of the total land area, of which ecosystems take up $91.92 \%$ by analysis of the elevation and slope. ${ }^{\text {ii }}$ These land use types include forests, grasslands and water bodies according to the land use classification system. ${ }^{\text {iii }}$ Orchards are one of the land use classification subcategories.

Table 2. Evaluation basis for the index of environmental stress.

\begin{tabular}{|c|c|c|}
\hline Index & Value & Evaluation Basis \\
\hline \multirow{3}{*}{$\begin{array}{l}\text { Water environment } \\
\text { stress }\end{array}$} & 5 & $\begin{array}{l}\text { River with a water quality standard of Grade V (seriously polluted); coastal area with water } \\
\text { quality standards of Grade IV and poorer. }\end{array}$ \\
\hline & 3 & $\begin{array}{l}\text { River with water quality standards of Grade IV (poor); Coastal area with a water quality } \\
\text { standard of Grade III. }\end{array}$ \\
\hline & 1 & $\begin{array}{l}\text { River with a water quality standard of Grade III (fair); coastal area with a water quality } \\
\text { standard of Grade II. }\end{array}$ \\
\hline \multirow{3}{*}{ Salinization stress } & 5 & Significant seawater intrusion and groundwater depression in estuarine or salty coastal areas. \\
\hline & 3 & Vulnerability to salinization in estuarine and silt coastal areas. \\
\hline & 1 & Coastal plain with elevation of $<5 \mathrm{~m}$ and average slope of $<1^{\circ}$. \\
\hline \multirow{3}{*}{ Soil erosion stress } & 5 & Other areas except ecological regions with slopes greater than $15^{\circ}$. \\
\hline & 3 & Orchards with slopes greater than $8^{\circ}$. \\
\hline & 1 & Other areas except ecological regions with slopes between $8^{\circ}$ and $15^{\circ}$. \\
\hline \multirow{3}{*}{$\begin{array}{l}\text { Coastal and island } \\
\text { erosion stress }\end{array}$} & 5 & $\begin{array}{l}\text { Long-term rate of erosion for sandy and silt coast averages } 3 \mathrm{~m} / \mathrm{a} \text { ("a" is year) and } 15 \mathrm{~m} / \mathrm{a} \text {; } \\
\text { islands of significant inland value, richness of abundant marine species and habitats. }\end{array}$ \\
\hline & 3 & $\begin{array}{l}\text { Long-term rate of erosion for sandy and silt coast averages } 2 \text { to } 3 \mathrm{~m} / \mathrm{a} \text { and } 10 \text { to } 15 \mathrm{~m} / \mathrm{a} \text {; younger } \\
\text { sandy islands in estuaries, with low vegetation coverage and declining water areas; }\end{array}$ \\
\hline & 1 & $\begin{array}{l}\text { Long-term rate of erosion for sandy and silt coast averages } 0.5 \text { to } 2 \mathrm{~m} / \mathrm{a} \text { and }<10 \mathrm{~m} / \mathrm{a} \text {; islands } \\
\text { with substantial lateral erosion in silt sea areas. }\end{array}$ \\
\hline
\end{tabular}


Step 2, integration of a single index: A spatial overlay analysis of a single index was carried out, processed by evaluating these eight indicators individually and taking the single-index evaluation result as the value of the area if the area is a single type. We determined the value of complicated areas in which several indicators spatially overlap by applying the principle of ecological importance priority and then analyzing the dominant indicators of these areas.

Step 3, identification of ERLs: Based on the overlay analysis and results of ecological importance and environmental stress, we analyzed and identified ERL zones and assigned each zone one of two grades (Table 3).

Table 3. Results of overlay analysis and assignment of grades. ERL, ecological red line.

\begin{tabular}{cccc}
\hline Ecological Importance & Environment Stress & Overlay Results & ERL Zone Grades \\
\hline 5 & 5 & 5 & Grades I \\
& 3 & & \\
& 1 & 3 & Grades II \\
3 & 5 & & \\
& 3 & & - \\
1 & 5 & 1 & \\
\hline
\end{tabular}

Note that the overlay analysis results with a value of 1 were considered negligible due to the minor levels of ecological importance and low environmental stress.

\section{Coastal ERL Identification}

\subsection{Ecological Importance Evaluation}

After a century of scientific research, forests have been confirmed to afford the best protection of water supplies and aquatic ecosystems [21]. Forests also present subtle differences in vegetation, soil properties and water flow pathways that lead to substantial differences in stream flow and water quality. Figure 3 shows that the highly important water conservation areas of Liaoning are scattered in the cities of Huludao and Dalian and concentrated in east central Xingcheng and Suizhong, south central Wafangdian, north Pulandian, southwest Zhuanghe and northeast Dandong. The vast forested areas of the eastern Heishan Mountain and western Qianshan Mountains are the main source of freshwater for the country, as well as a critical ecosystem, and their thick forests and abundant vegetation play a very important role in water conservation. Water conservation areas considered of moderate importance are widely spread in western Suizhong and Lianshan, southern Gaizhou, south central Dalian, northern Zhuanghe and western Dandong. Many forests used for commercial and economic purposes could also be used for water conservation. The areas in which water conservation is of minor importance are scattered over most of Panjin City, Linghai and southwest of Dandong. However, residents of these areas have to be very aware of the vulnerability of the ecosystem.

Conserving as many plants and animals as possible is important for humans and other species. Today, the most significant threats to biodiversity include habitat destruction and alteration, pollution and climate change. Conservation scientists recognize that global climate change during this century 
threatens current ecosystems at the species level [22]. Coastal areas are especially vulnerable to climate change. Figure 3 shows that the areas of high importance for species conservation are mainly distributed in the coastal regions of Panjin, Dalian and Dandong. These areas have complicated ecosystems and a high diversity of species, including various nature reserves, such as the Spotted Seal National Nature Reserve in Dalian with many aquatic mammals, the Snake Islands in Liaoning with numerous reptiles and amphibians, the Shuangtaizi Estuarine Wetland represented by migratory waterbirds and the Sanshan Islands Marine Products Reserve containing exiguous fish and aquatic resources. The areas that are of moderate importance for species conservation are spread out in Lushunkou and northwest of Gaizhou, as well as on the border of Zhuanghe and Dandong. In these areas, protected natural forests preserve various and abundant biological species. The areas of minor importance for species conservation are scattered in the northwest of Suizhong and Xingcheng, the northeast of Wafangdian and northern Pulandian. These areas have an abundance of plants that produce oxygen and provide resources for industry.

Conservation of wetlands is aimed at protecting and preserving areas where water exists at or near the surface of the land. Wetland conservation originally focused on the function of providing a habitat for waterbirds; then, its scope broadened to emphasize the sensible use of the wetland. This development reflects the increasing recognition of the importance of wetlands as ecosystems that significantly contribute to the maintenance of biodiversity, as well as to the economy for water supply, fisheries, agriculture, forestry and tourism. According to prior research, erosion and wetland loss due to global climate change will alter coastal regions, while increasing ocean acidification affects the entire ocean system [23]. High-importance wetland conservation areas of the coastal region in Liaoning are mainly distributed in Dandong, Panjin and Dalian, including the Yalu River wetland in Dandong, the Shuangtaizi Estuarine wetland in Panjing, and wetlands in the estuaries of the Yingna, Zhuang, Liaohe and Liugu rivers. The moderately important wetland conservation areas range from coastal zones in Suizhong to Xingcheng, consisting of swamps and riverine wetlands. Some of these areas could be developed for aquafarm and reclamation, but such development would make these areas ecologically inferior to the high-importance areas. The areas of minor importance for wetland conservation are located in Linghai, north central Panshan, southwest Zhuanghe and northeast Dandong and are characterized by reedy areas. Land use changes or hydrological modifications would destroy the functions that wetlands naturally provide.

The goal of coastal and island conservation is to protect and conserve the coastal zone, as well as the adjacent lands and wetland ecosystems, by reducing the impacts of projects and by promoting and enhancing the present and future availability of these coastal resources for the benefit and enjoyment of the general public [24]. Figure 3 clearly shows that the high-importance coastal and island conservation areas are distributed in the southwest of Xingcheng, Suizhong and Jinzhou cities, the northwest of Bayuquan and Jinzhou counties, southern Lushunkou, southwest Jinzhou County and the majority of the Changhai islands. These types of coasts and islands provide beautiful beaches and profuse marine resources, which could be potential contributors to the economy in the long term. The moderately important coastal and island conservation areas are scattered in the northwest of Gaizhou and Lushunkou and southwest Zhuanghe, where the sandy and silty coasts have lengths of $<10 \mathrm{~km}$, with gulf landscapes and fair beaches. The coastal and island conservation areas of minor importance are mainly concentrated in western Wafangdian, the center of the Changhai islands and adjacent islands. 


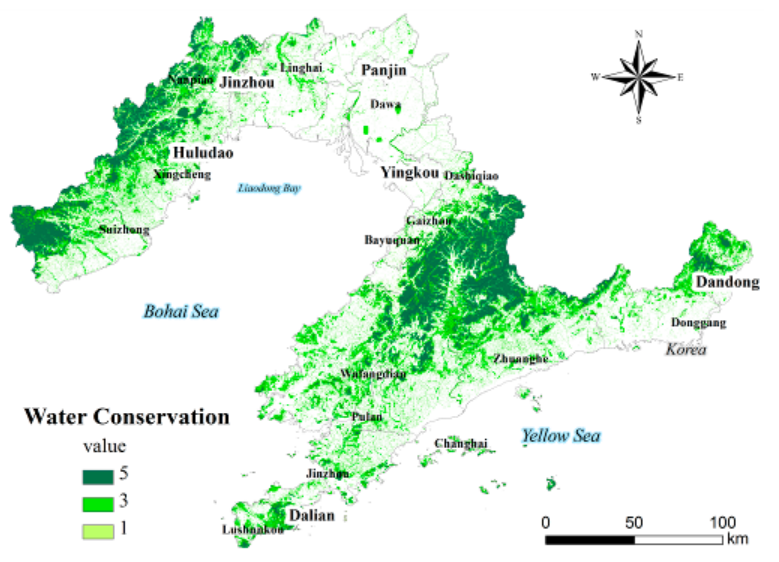

(a)

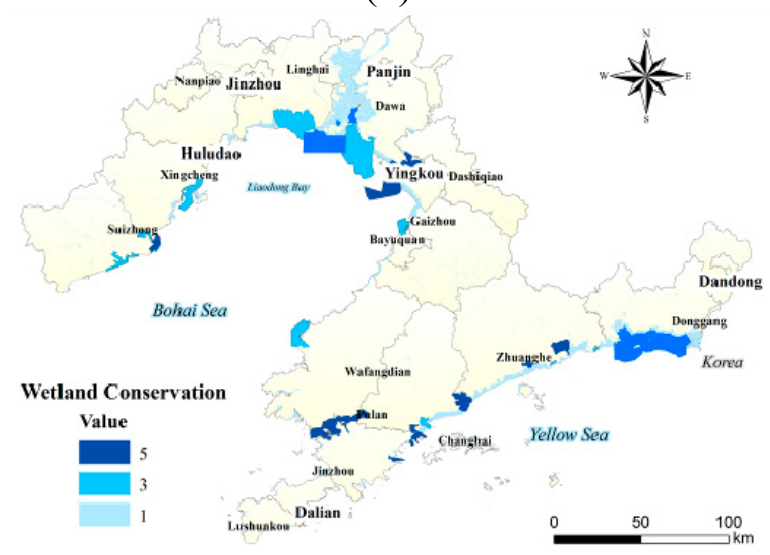

(c)

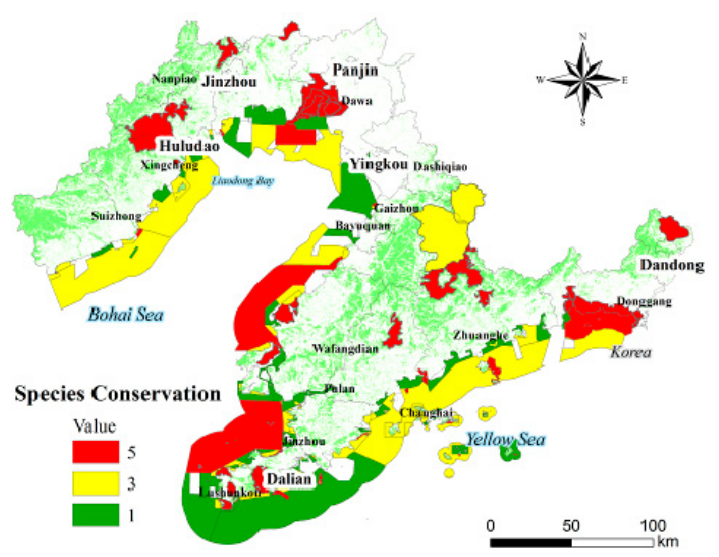

(b)

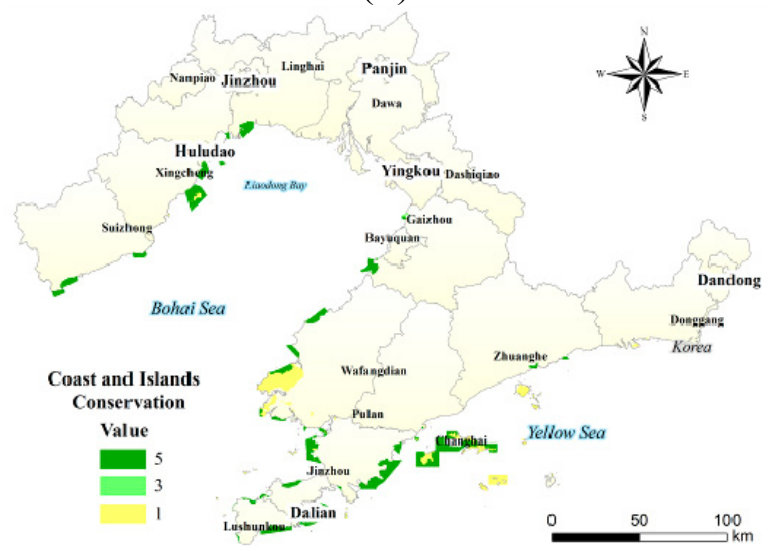

(d)

Figure 3. Map showing the four indices of ecological importance evaluations: (a) water conservation; (b) species conservation; (c) wetland conservation; (d) coast and islands conservation.

Figure 5 depicts the combined evaluations based on the results of the four single indices of ecological importance. The areas of high ecological importance were determined to be in eastern Suizhong and Xingcheng, west central Lianshan, southern Dawa, central Pulandian, northern Zhuanghe, southern Donggang and northeast Dandong. These areas have high conservation values as they contain well-preserved forests, diverse species and functioning ecosystem services, and their preservation should be prioritized in the long term. The areas of moderate ecological importance are in western Suizhong, northwest Xingcheng, north central Panshan, on the borders of Wafangdian and Pulandian, Pulandian and Zhuanghe, as well as northern Donggang and western Dandong. These areas provide great landscapes and ecological services that should be properly protected by implementing effective compensatory mitigation. The areas of minor ecological importance are focused in western Yingkou, northern Panjin and southwest Dalian. The ecosystem function of these areas is declining, and any remaining ecological function should be preserved by not subjecting them to economic development in the coming years.

\subsection{Environment Stress Evaluation}

Water stress occurs when poor quality restricts its use, which causes deterioration of the quantity and quality of fresh water resources, including by eutrophication, organic matter pollution and saline 
intrusion. The degradation of water quality has been noticeable in recent years in the urban and industrial areas along the coast. The areas with high water environmental stress are distributed in the Jinzhou section of the Xiaoling River, the Linghai section of the Daling River, the Yingkou section of the Liaohe River, the Gaizhou section of the Qing River and the estuary of the Shuangtaizi River (Figure 4). Rivers in these areas suffer from heavy pollution, and major pollutants affecting the quality of the coastal water include inorganic nitrogen and active phosphate, which should be controlled by effective mitigation. The areas with moderate water environmental stress are scattered in the estuaries of the Liugu, Xingcheng, Daling, Xiaoling and Shuangtaizi rivers, as well as sections of the Fuzhou and Dengsha rivers. These areas are moderately polluted: $60.6 \%$ of the total water in these areas have a quality inferior to the Grade IV standard. The areas with low water environmental stress are located in the Zhuang River, the Fuzhou Gulf and the Biliu River. Most of the rivers in these areas were observed to be slightly polluted. The major pollutants affecting the coastal water quality in these areas were observed to be inorganic nitrogen and active phosphate, monitored respectively at levels of $28.6 \%$ and $15.9 \%$ in excess of the proposed maximum contaminant level. Although the water quality of the Bohai Sea has improved and that of the Yellow Sea has been stable in recent years, long-term monitoring and management are still recommended.

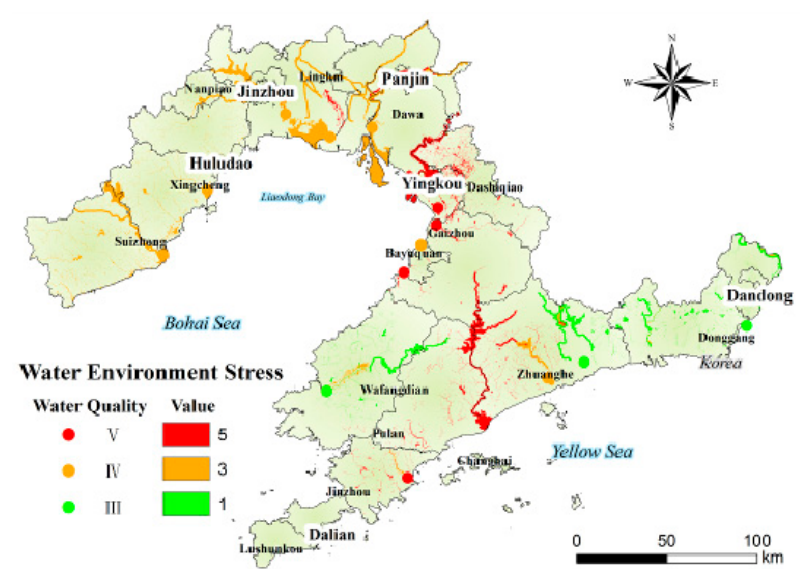

(a)

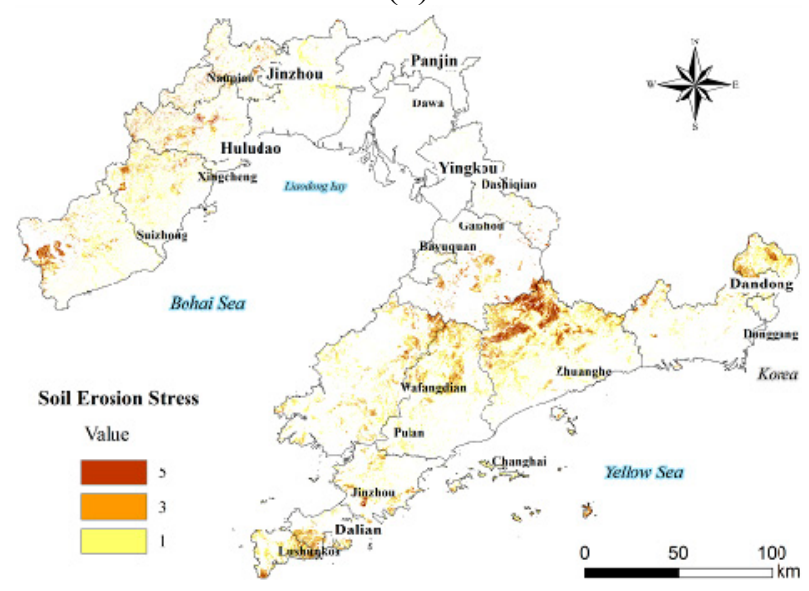

(c)

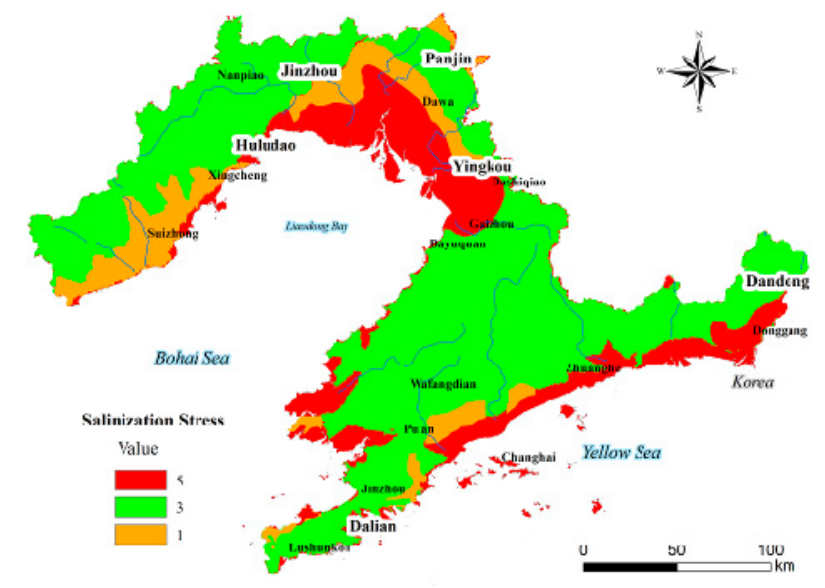

(b)

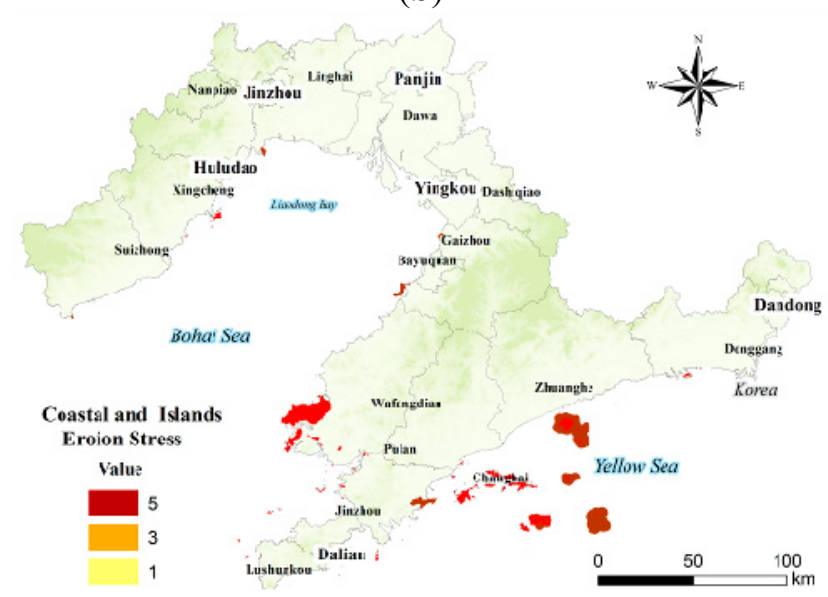

(d)

Figure 4. Map showing the four indices: (a) water environment stress; (b) salinization; (c) soil erosion stress; (d) coastal and islands erosion stress based on the environment stress evaluation results. 
Like water pollution stress, high concentrations of soluble salts pose another problem for humans. Intrusion of saline water has adverse effects on freshwater, soils, agriculture, fisheries, ecosystems and livelihoods in the Liaoning region. A progressive increase in salinity has degraded arable land, which, in turn, is rapidly increasing desertification and salinization worldwide [25]. In addition, coastal wetlands are threatened by increases in salinity as a result of both natural processes and human-induced hydrologic alterations. Coastal areas in Liaoning are currently experiencing higher than expected salinities in traditionally freshwater marshes and waterways. The areas experiencing stress from high salinity are mainly distributed in southwest Panshan, northern Gaizhou, Liaohe River regions and southern Dongang. These areas have become seriously salinized due to heavy development of the bare lands adjacent to the reedy wetlands, and this has become a serious environmental problem. The areas experiencing moderate salinity stress cover most of the study area, ranging from southern Suizhong to northern Panshan, southern Bayuquan, southwest Gaizhou and northwest Lushunkou. Here, plenty of areas rich with reeds were observed to be effectively functioning, i.e., preventing intrusion of saline water. Areas with little stress due to salinity were observed to extend from the coastline inland toward Suizhong, Panjin and southeast of Wafangdian. Note that abundant intertidal organisms provide a strong response to environmental stress in general and to salinity stress specifically. When stress is detected prior to visible damage, introducing such organisms as well as managing the landscape could be part of a quick and accurate response to the stress. Detection of environmental stress prior to visible damage would allow for the formulation of a quick and accurate response to the stress by appropriate alterations of the landscape.

Although wave action is the obvious contributor to coastal soil erosion and landslide activity, there are many other factors involving the climate, as well as the nature of the soil [26]. Certain topographical features, such as shallow layers of soil, growing coastal populations and the growth of coastal tourism, are the key factors contributing to increased sedimentation and soil erosion [5], which are primary environmental problems in coastal areas. The areas experiencing stress due to high soil erosion are distributed in western Suizhong and southern Gaizhou, which are near the Qingshan and Qianshan mountains. These regions are characterized by complicated geologic structures, active rifts, frequent earthquake activity and vertical, as well as lateral erosion. These factors contribute to thin layers of soil that are prone to increasing erosion. The areas with moderate soil erosion stress are spread all over the coastal region, especially in northwest Huludao and Jinzhou, western Panjin, south central Yingkou and western Dalian. The low soil erosion stress areas are distributed in central Linghai, southern Suizhong and northeast Dandong. The strong northeast winds on the dry plains of the eastern coasts have caused tremendous loss of soil in the past few decades. This erosion could be controlled by establishing windbreaks and increasing vegetative cover on the bare land.

Coastal and marine resources are subject to many erosive influences. Along the coast, cycles of beach, island and cliff erosion have been related to extreme weather that affect coastal erosion, which is already a widespread problem that has significant impacts on undeveloped shorelines, as well as on coastal development and infrastructure [27]. Storms could cause great erosion events on the Liaoning coasts and islands, and the slopes of these areas are so gentle, that a small rise in sea level produces a large inland shift of the shoreline. This shift increases the threats to coastal development, transportation, infrastructure, tourism, freshwater aquifers and fisheries. The coasts and islands experiencing high soil erosion stress are concentrated in southern Dandong, northeast Zhuanghe and Pulandian, the majority of 
the Changhai islands and small areas in southern Linghai. The moderately-stressed areas are concentrated in northern Liaodong Bay, especially on the borders of Panjin and Jinzhou. The southwest Zhuanghe area has experienced moderate erosion in recent years. It was also determined that most of the surface of the land of Linghai and southern Dawa is affected by soil degradation processes. These areas, while still stable and considered to be experiencing low levels of soil erosion stress, have nevertheless a high possibility of adversely affecting downstream communities and the natural environment by increasing the risk of flooding and causing damage through deposition of silt.

We also combined the results of the four single indices for environmental stress. As shown in Figure 5, the areas with high combined environmental stress are concentrated in central and eastern regions of study area, including western Panjing and Suizhong, south central Yingkou and southern Dandong. Areas experiencing moderate combined environmental stress are widely distributed in the northwest of Huludao and Linghai, stripped areas from Dawa connected to Dashiqiao, as well as western Pulandian. The remaining areas in the study area are characterized by overall low environmental stress; while they are stable, they do affect the coastal regions, albeit to a minor degree. Climate change in this area is likely to add to the cumulative impact of both natural and human-caused stresses on ecological systems and resources, which makes devising adaptation strategies particularly challenging.

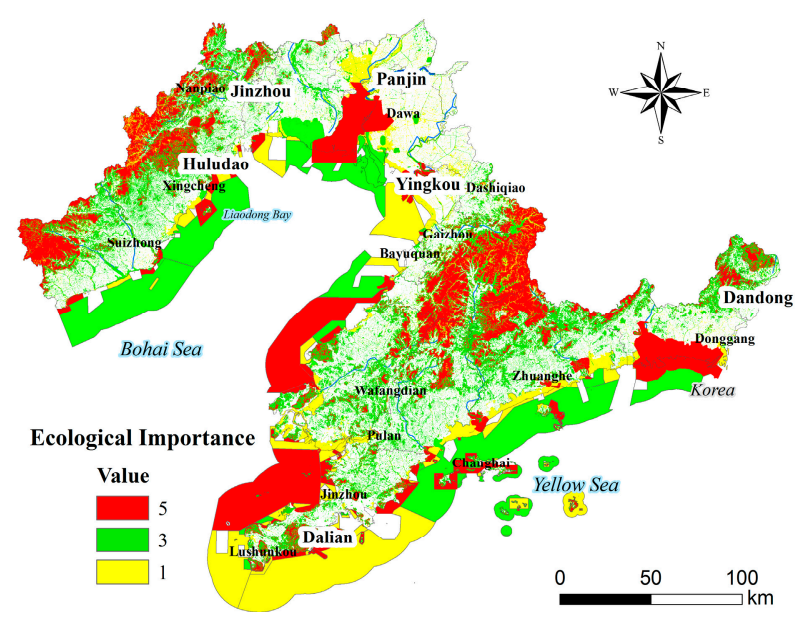

(a)

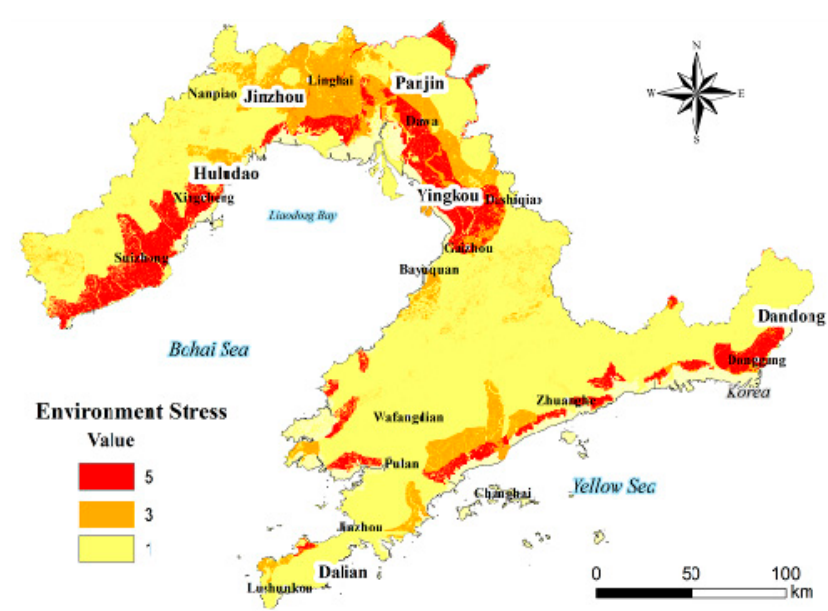

(b)

Figure 5. The results showing the areas of (a) ecological importance and (b) environmental stress, each at three different levels.

Based on the overlay analysis and the evaluation of the results of ecological importance and environmental stress, the ERL zones of the Liaoning coast were classified into two grades, as shown in Figure 6.

Grade I ERL zones were determined to contain the areas with critical and diverse ecosystem services, areas of high importance for species conservation and with nature reserves, as well as ecologically-vulnerable and sensitive areas. These areas were observed to be concentrated in northern Suizhong and Huludao, eastern Yingkou and northern Dalian, as well as the Shuangtaizi estuarine zone, the Yalu River Delta seashore wetland nature reserves in Dandong and the spotted seal conservation areas in Dalian. They have significant effects on ecological function, in particular on maintaining biological diversity and improving the quality of the ecological environment, which should be strictly 
protected and explicitly controlled. Any human activities and further development should be strictly forbidden in these areas to maintain long-term ecological security.

Grade II ERL zones are the areas with minimum requirements for maintaining the basic needs of a livable environment and human health for local residents with moderate to minor levels of ecological importance and in which the coastal ecosystem services delivered are less important than in Grade I ERL zones. These areas were shown to stretch from the estuarine zones of the Liugu, Daling, Shuangtaizi, Daliao, Biliu and Yingna rivers to the Yalu River Delta and to experience high to moderate levels of environmental stress, such as sea water intrusion and soil erosion. It is indicated that further preservation and protection in these areas should strictly comply with the environmental management policy to prevent the quality of the ecological environment from decreasing below a minimum level.

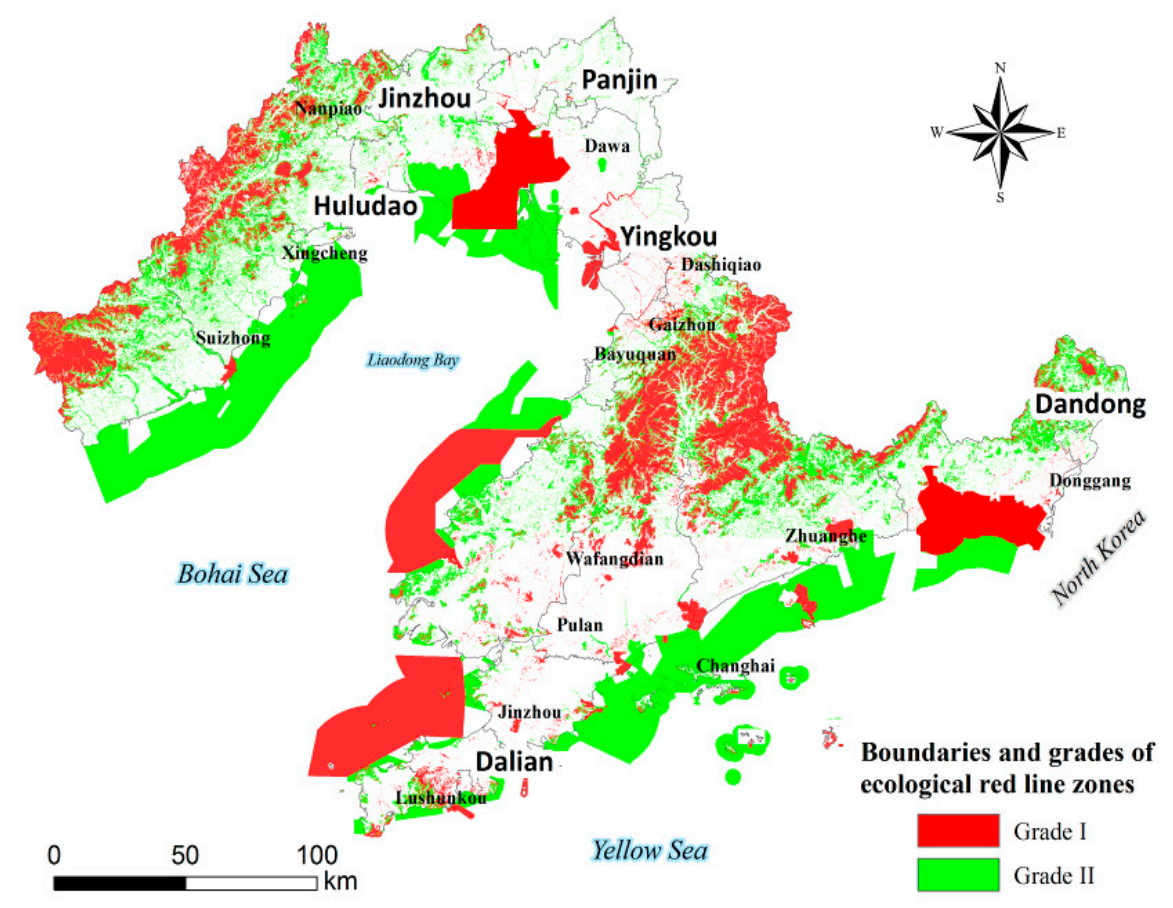

Figure 6. Map showing the two grades of ERL zones in both terrestrial and marine areas and their boundaries.

\section{Conclusions and Discussion}

The term ERL refers to a baseline that must be maintained to improve ecosystem functions [28]. Scientifically, identifying ERLs could facilitate tailoring the economic development and environmental protection in a local region to its particular natural and environmental characteristics. Areas protected by ERLs could require ecological compensation or payment for use of resources. The red line system could also factor into evaluating the environmental performance of government officials.

This paper defined the ERL by evaluating ecological importance and environmental stress that is strategically important to protecting national and regional environmental security. The boundaries of the ERL were determined by analyzing the dominant environmental factors in the ecosystems at the site level. According to our evaluations, the 24 areas of high ecological importance, whose importance is mainly dominated by species conservation, accounting for $90.2 \%$ of the total conservation areas, including $79.2 \%$ of the marine species conservation areas. These ecologically important areas are 
undergoing major environmental stresses, such as water pollution and intrusion of saline water into estuarine and coastal areas, which means that the implementation of identified policies in coastal areas is important for their sustainable resource management.

We classified two grades of ERL zones. Grade I ERL zones were considered to contain the areas with critical and diverse ecosystem services, highly important areas for species conservation, nature reserves, as well as ecologically vulnerable and sensitive areas. These areas have significant effects on ecological function, in particular for improving the quality of the ecological environment, which should be explicitly controlled. Grade II ERL zones are the areas with minimum requirements for maintaining the basic needs of a livable environment and human health for local residents with moderate to minor levels of ecological importance and in which the coastal ecosystem services delivered are less important than in Grade I ERL zones. These areas also experience high to moderate levels of environmental stress, such as sea water intrusion and soil erosion. It is indicated that further preservation and protection in these areas should strictly comply with the environmental management policy to prevent the quality of the ecological environment from decreasing below a minimum level.

Although the term "ecological red line" is used frequently by politicians and the media, exactly what constitutes an ERL remains unclear. The present lack of clarity about the concept has not prevented a number of government departments, such as the State Forestry Administration, the Ministry of Water Resources and the Ministry of Environmental Protection (MEP), from issuing their own "red lines", which could be either quantitative or qualitative [29]. Furthermore, defining red lines is of little value unless they are actually implemented. The complexity of defining red lines lies in how to set the red lines at different administrative levels. While it may be relatively easy to set the red lines nationally, it may take more time and effort to scale them down to the city and county levels. Moreover, there are many other challenges to be faced: red lines must match up with regional ecological and land use plans. In some pilot projects, government authorities found that land that was considered to require protection had been earmarked and approved for development in legislative land use plans [30]. The red lines will ultimately be enforced by local governments, which would conflict with those of the MEP. Setting up an ecological inventory through remote sensing satellites and ground-level monitoring and appraising the effectiveness of protection dynamically could better ensure that appropriate ERLs are observed.

\section{Acknowledgments}

This work was supported by National Natural Science Foundation of China (41171109) and the Key Program of the Chinese Academy of Sciences (KZZDEW0603).

\section{Author Contributions}

This research was designed by Chuansheng Wang; Guiyan Sun and Lijuan Dang collected and analyzed the data and wrote and revised the paper. All authors have read and approved the final manuscript.

\section{Conflicts of Interest}

The authors declare no conflict of interest. 


\section{References}

1. Gallup, J.L.; Sachs, J.D.; mellinger, A.D. Geography and economic development. Int. Reg. Sci. Rev. 1999, 22, 179-232.

2. United Nations Environment Programme. Marine and Coastal Ecosystems and Human Wellbeing: A Synthesis Report Based on the Findings of the Millennium Ecosystem Assessment; UNEP: Nairobi, Kenya, 2006.

3. He, Q.; Bertness, M.D.; Bruno, J.F.; Li, B.; Chen, G.; Coverdale, T.C.; Altieri, A.H.; Bai, J.; Sun, T.; Pennings, S.C.; et al. Economic development and coastal ecosystem change in China. Sci. Rep. 2014, 4, 1-8.

4. Ives, A.R.; Carpenter, S.R. Stability and diversity of ecosystems. Science 2007, 317, 58-62.

5. Carpenter, S.R.; Mooney, H.; Agard, J.; Capistrano, D.; DeFries, R.; Diaz, S.; Dietz, T.; Duraiappah, A.K.; Oteng-Yeboah, A.; Pereira, H.M.; et al. Science for managing ecosystem services: Beyond the Millennium Ecosystem Assessment. Proc. Natl. Acad. Sci. USA 2009, 106, $1305-1312$.

6. Ministry of Environmental Protection of the People's Republic of China. The Marine Environmental Quality Report of 2012; Ministry of Environmental Protection of the People's Republic of China: Beijing, China, 2013; Volume 6.

7. Zong, Y.G.; Wang, R.; Wang, C.-G.; Wang, H.-Y.; Zhang, L. Ecological suitability assessment on land use based on potential constrain approach: The case of urbanized areas in Dalian City, China. Geogr. Res. 2007, 26, 1117-1125.

8. Fan, J.; Qian, Q.L. A comparative-study on the interactive relations between economic development and resource-environment in China's eastern coastal areas. J. Nat. Resour. 2004, 19, 96-105.

9. Briner, S.; Elkin, C.; Huber, R. Evaluating the relative impact of climate and economic changes on forest and agricultural ecosystem services in mountain regions. J. Environ. Manag. 2013, 129, 414-422.

10. Thomas, C.D.; Cameron, A.; Green, R.E.; Bakkenes, M.; Beaumont, L.J.; Collingham, Y.C.; Erasmus, B.F.N.; de Siqueira, M.F.; Grainger, A.; Hannah, L.; et al. Extinction risk from climate change. Nature 2004, 427, 145-148.

11. Klijn, F.; de Haes, H.A.U. A hierarchical approach to ecosystems and its implications for ecological land classification. Landsc. Ecol. 1994, 9, 89-104.

12. Parmesan, C.; Yohe, G. A globally coherent fingerprint of climate change impacts across natural systems. Nature 2003, 421, 37-42.

13. Chen, K. A Study on Migratory Waterbirds and Wetlands in the Yellow Sea; China Forestry Press: Beijing, China, 2006.

14. Luan, X.F.; Huang, W.N.; Wang, X.L. Identification of hotspots and gaps for biodiversity conservation in Northeast China based on a systematic conservation planning methodology. Acta Ecol. Sin. 2008, 29, 144-150.

15. Wang, R.P.; Chen. K. Analysis of the situation and problems in reverting farmland to forests and grassland in China. Res. Soil Water Conserv. 2006, 13, 188-192. 
16. Lai, Y.C.; Li, X.W.; Feng, S.; Wang, P.; Tang, J.-P.; Zhao, A.-J.; Lai, J.-M. Impact of Grain for Green project on ecosystem service values in the hilly region in Sichuan basin: A case study of Hongya County. J. Nat. Resour. 2011, 26, 755-768.

17. The Political Bureau of the Central Committee. Communique of the Third Session of the Eighteenth Central Committee of the Communist Party of China; The Political Bureau of the Central Committee: Beijing, China, 2013.

18. Zhang, X.L.; Yu, D.M.; Feng, A.P.; Ding, D. Restoration of degraded coastal wetlands in the Southern Laizhou Bay. Marine Sci. 2004, 28, 49-53.

19. Han, G.F.; Zhao, K.; Yuan, X.; Sun, R. Evaluation of ecological sensitivity in mountain area based on spatial analysis: A case study of Wanyuan City in Sichuan Province. J. Mountain Sci. 2008, 26, 531-537.

20. Ministry of Environmental Protection of the People's Republic of China. The National Ecological Function Zoning; Ministry of Environmental Protection of the People's Republic of China: Beijing, China, 2008.

21. Knight, A.T.; Cowling, R.M.; Rouget, M.; Balmford, A.; Lombard, A.T.; Campbell, B.M. Knowing but not doing: Selecting priority conservation areas and the research implementation gap. Conserv. Biol. 2008, 22, 610-617.

22. Bailey, C.H.; Chen, M. Morphological basis of long-term habituation and sensitization in Aplysia. Science 1983, 220, 91-93.

23. Baumgärtner, S.; Dyckhoff, H.; Faber, M.; Proops, J.; Schiller, J. The concept of joint production and ecological economics. Ecol. Econ. 2001, 36, 365-372.

24. Groot, R.S.; Alkemade, R.; Hein, L.; Willemen, L. Challenges in integrating the concept of ecosystem services and values in landscape planning, management and decision making. Ecol. Complex. 2010, 7, 260-272.

25. Roy, H.Y.; Marion, P.; Felix, K. Indicators of ecosystem service potential at European scales: mapping marginal changes and trade-offs. Ecol. Indic. 2012, 21, 39-53.

26. Costanza, R.; Pérez-Maqueo, O.; Martinez, M.L.; Sutton, P.; Anderson, S.J.; Mulder, K. The value of coastal wetlands for hurricane protection. AMBIO J. Hum. Environ. 2008, 37, 241-248.

27. Bennett, E.M.; Peterson, G.D.; Gordon, L.J. Understanding relationships among multiple ecosystem services. Ecol. Lett. 2009, 12, 1394-1404.

28. Yang, B.J.; Gao, J.X.; Zou, C.X. The strategic significance of drawing the ecological protection red line. China Dev. 2014, 14, 1-4.

29. Zhen, H.; Ouyang, Z.Y. Practice and consideration for ecological redlining. Ecosyst. Serv. Assess. 2014, 29, 457-461, 448.

30. Wang, C.F.; Jiang, Q.H. Discussion on the legal system guarantee of ecological red line. Environ. Prot. 2014, 12, 30-33.

(C) 2015 by the authors; licensee MDPI, Basel, Switzerland. This article is an open access article distributed under the terms and conditions of the Creative Commons Attribution license (http://creativecommons.org/licenses/by/4.0/). 